\title{
Lung disease after exposure to polyvinyl chloride dust
}

\author{
M ANTTI-POIKA, H NORDMAN, J NICKELS, H KESKINEN, A VILJANEN \\ From the Institute of Occupational Health, Helsinki, and Meltola Hospital, Karjaa, Finland
}

Cases of lung disease after exposure to polyvinyl chloride (PVC) dust have been described. ${ }^{12}$ The association bétween pneumoconiosis and PVC dust is also supported by animal experiments $^{3-5}$ and epidemiological studies. ${ }^{6-8}$

\section{Case report}

A 41 year old man who worked at a PVC factory and had suffered from daily cough and gradually increasing dyspnoea since July 1981 has been followed since February 1982. He had smoked one package of cigarettes daily for 20 years.

The patient had worked in a PVC factory from 1974 but had an accumulated exposure to PVC dust of only about 750 days. Total dust concentrations during packing of PVC ranged from 0.3 to $42 \mathrm{mg} / \mathrm{m}^{3}$ (median of 38 measurements $\left.2 \mathrm{mg} / \mathrm{m}^{3}\right)$. He had worked for a total of 60 days in the most dusty work phases. He had been exposed to relatively low concentrations $(0-3 \mathrm{ppm})$ of vinyl chloride monomer (VCM). He had not been exposed to asbestos or other known fibrogenic agents. PVC had been considered harmless because of the large mean particle size given by the producer $(20-200 \mu \mathrm{m})$. When we examined dust samples from the workroom air by electron microscopy, however, most of the particles were smaller than $1 \mu \mathrm{m}$.

Subjectively, the patient's performance capacity had declined but his clinical condition was normal. The chest radiograph was within normal limits. Spirometry yielded normal values but diffusing capacity transfer factor (TLCO), was abnormal (TLCO $45 \%$, KCo $36 \%$ of predicted normal values). An ergometer bicycle test (50 and $100 \mathrm{w}$ for four minutes, $150 \mathrm{w}$ for two minutes) resulted in moderate hypoxaemia (arterial oxygen tension $8.5 \mathrm{kPa}(63.8 \mathrm{~mm} \mathrm{Hg})$, arterial carbon dioxide tension $3.6 \mathrm{kPa}(27 \mathrm{~mm} \mathrm{Hg}), \mathrm{pH} 7.36)$. The oxygen saturation was lowered from $94 \%$ to $89 \%$ during the test.

The results of routine laboratory tests were normal, and so were the results of a large panel of immunological tests, including nuclear antibodies, DNA antibodies, number of T and $B$ lymphocytes in peripheral blood, immunoglobulin and complement $\left(\mathrm{C}_{3}, \mathrm{C}_{4}\right)$ concentrations, and phytohaemagglutinin stimulation of lymphocytes. $\alpha_{1}$ antitrypsin concentration was $3.1 \mathrm{~g} / \mathrm{l}$ (phenotype MM). The appearance of the bone marrow aspirate was normal.

A thoracotomy was performed and histological examination of part of the lingula showed a profuse accumulation

Address for reprint requests: Dr Mari Antti-Poika, Institute of Occupational Health, Topelinksenk 71aA, SF-00250 Helsinki, Finland.

Accepted 9 December 1985 of macrophages with some haemorrhage and an increase in $\vec{\overrightarrow{ }}$ elastic and collagenous fibres. In the broncho-alveolar $\omega$ lavage fluid $82 \%$ of the cells were macrophages, many resembling foreign body giant cells. Some ferruginous $\times$ bodies were also seen.

Sudan IV stains polyvinyl chloride powder red after treat $-\vec{V}$ ment with alcohol and acetone in ordinary paraffin sec-i tions. ${ }^{9}$ The alveolar macrophages of our patient containedo abundant Sudan positive particles. The particles stained dark blue in Epon sections after toluidine blue treatment (fig 1). Electron microscopic examination showed that the particles were electron dense, which is in agreement with earlier findings. ${ }^{4} X$ ray microanalysis showed chlorine inaddition to osmium in the particles (fig 2), whereas in other parts of the cells only osmium was detected from the osmium ${ }^{\circ}$ tetroxide used as postfixative in Epon embedding. These observations suggest that the phagocytosed material was PVC dust.

The patient had since the spring of 1982 received bron chodilators, which had given him relief of symptoms although no improvement in pulmonary function was detectable. In June 1983 treatment with prednisolone was $\overrightarrow{\bar{\sigma}}$ started $(60-15 \mathrm{mg}$ for three months). No clear effect was seen. The patient was provided with domiciliary oxygen in? 1984, which gave him subjective relief.

\section{Discussion}

Epidemiological $^{6-8}$ and experimental studies ${ }^{3-5}$ suggest an association between exposure to PVC and pulmonary radio- -3 graphic and histological changes. In most of these studies no-

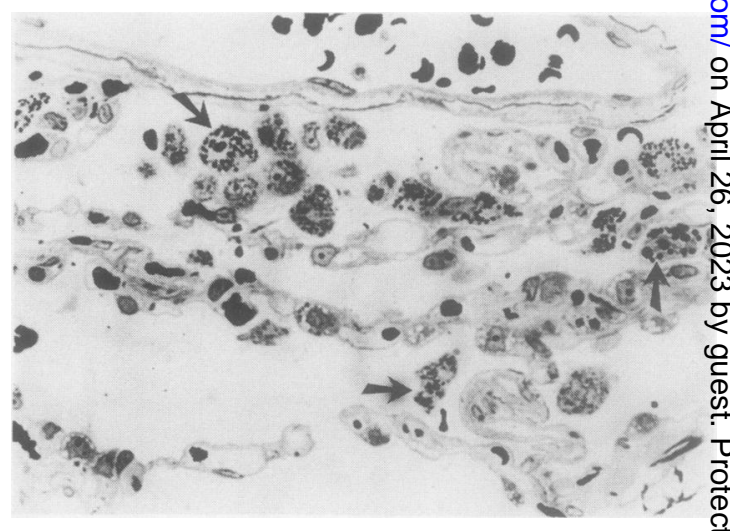

Fig 1 Light micrograph of $1 \mu$ thick Epon section showing intra-alveolar macrophages containing dark granules (arrows). (Toluidine blue.) 


\section{Counts}

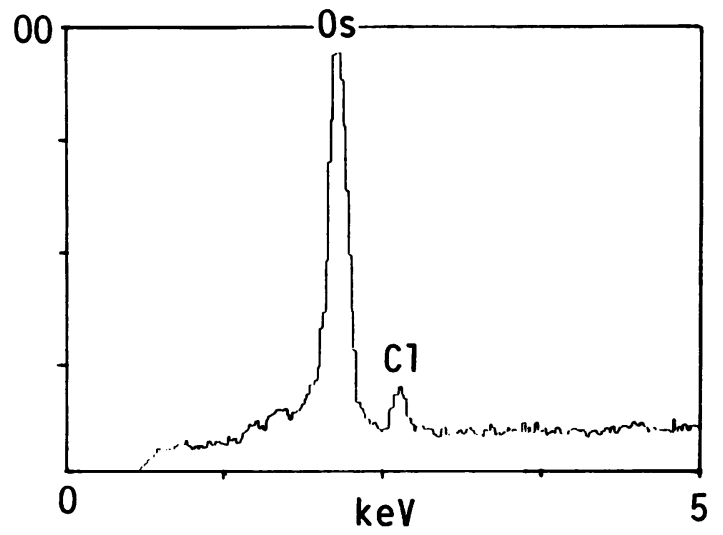

Fig 2 Elemental electron probe microanalysis from a granule of a macrophage showing chloride and osmium.

severe fibrosis or impairment of lung function has been found.

Our patient had severe dyspnoea and a substantial decrease in transfer factor (diffusing capacity). The clinical picture in previous case reports has varied from slight reduction in vital capacity ${ }^{2}$ to severe dyspnoea. ${ }^{1}$ It has been suggested that severe impairment of pulmonary function and especially of transfer factor is associated with exposure to VCM rather than to PVC dust. ${ }^{10}$ Our patient, however, had been only minimally exposed to VCM. He was considerably disabled despite the fact that both the duration and the level of exposure had been moderate, whereas most of the previously described patients had been heavily exposed for long periods.

Several features of our case incriminate PVC in the aetiology of the pulmonary disease, including the histological findings, which resembled those of other reported cases $^{12}$ and the findings in animal experiments ${ }^{4}$; the alveolar lumina were packed with macrophages, which contained masses of phagocytosed material that was shown histochemically to consist of PVC particles. Nevertheless, the causal association between PVC and the disease remains open. Preliminary results (unpublished) of experiments on the phagocytosis of different PVC particles studied with a chemiluminescence assay indicate different effects on neutrophils of various technical PVC grades. Thus differences between PVC grades may explain different responses to PVC dusts and variations in clinical features. Additional studies are needed to confirm the association between PVC and lung disease and to clarify the mechanisms of any disease identified.

\section{References}

1 Szende B, Lapis K, Nemes A, et al. Pneumoconiosis caused by the inhalation of polyvinylchloride dust. Med Lav 1970;61:433-6.

2 Arnaud A, Pommier De Santi P, Garbe L, et al. Polyvinylchloride pneumoconiosis. Thorax 1978;33:19-25.

3 Frongia N, Spinazzola A, Bucarelli A. Lesioni polmonari sperimentali da inalazione prolungata di PVC in ambiente di lavoro. Med Lav 1974;65:321-42.

4 Groth DH, Lynch DW, Moorman WJ, et al. Pneumoconiosis in animals exposed to polyvinylchloride dust. Environ Health Perspect 1981;41:73-81.

5 Richards RJ, Cobb LM, Hardy CJ, et al. Effects in rats of inhaling PVC dust at the nuisance dust level $\left(10 \mathrm{mg} / \mathrm{m}^{3}\right)$. Arch Environ Health 1981;36:14-9.

6 Soutar CA, Copland LH, Thornley PE, et al. Epidemiological study of respiratory disease in workers exposed to polyvinylchloride dust. Thorax 1980;35:644-52.

7 Mastrangelo G, Saia B, Marcer G, et al. Epidemiological study of pneumoconiosis in the Italian polyvinylchloride industry. Environ Health Perspect 1981;41:153-7.

8 Soutar CA, Gauld S. Clinical studies of workers exposed to polyvinylchloride dust. Thorax 1983;38:834-9.

9 Wilson N. A method for staining polyvinyl chloride in sections using Sudan IV. Stain Technol 1979;54:101-2.

10 Lloyd MH, Gauld S, Copland L, et al. Epidemiological study of the lung function of workers at a factory manufacturing polyvinylchloride. Br J Ind Med 1984;41:328-33. 